\title{
Synchronous Multifocal Osteosarcoma
}

National Cancer Institute

\section{Source}

National Cancer Institute. Synchronous Multifocal Osteosarcoma. NCI Thesaurus. Code C6471.

A bone osteosarcoma affecting multiple skeletal sites, with multifocal lesions discovered within 6 months of the appearance of the initial tumor. It has a poor prognosis. 